${ }^{I}$ Research Scholar, Department of Management Studies, KL Business School, KL University (Deemed to be University), Green Fields, Vaddeswaram, Guntur, Andhra Pradesh, India

${ }^{2}$ Professor, Department of Management, KL University (Deemed to be University), Vaddeswaram, Guntur, Andhra Pradesh, India

\begin{abstract}
With word of moving towards digitization and latest technological trends India doesn't lie be hand any more in fact, India is emerging as a country that would give neck ton neck. Competition to the financial giants in terms of fintech establishment. Fintech might subsist a financial technology that describe an budding financial services sector within the 21 st century originally the term applied to technology applied to the back-end of recognized consumer and trade financial institutions. Fintech companies are essentially those Business organizations that situate technology to use within the context of finance put finance and technology together they generate optimized business results and supply better quality product service out come to the consumers.

KEYWORDS: Initiatives such as Jan Dhan Yojana, Aadhar and emergence of UPI, Banking Technology Solutions including B2B Products
\end{abstract}

Received: Jun01, 2020; Accepted: Jun20, 2020; Published:Jul09, 2020; Paper Id.: IJMPERDJUN2020252

\title{
INTRODUCTION
}

Financial Technology involves secure communication to others during a market through common language with a quick delivery of knowledge and news which can be public or privates and this is often done through a communication network. Financial Technology includes trading technology almost like that of economic systems. Trading includes several actions such auctioning, negotiating, buying, selling, borrowing, leasing, brokering, dealing The term 'fintech' has appeared recently in business journals to describe the disruptive challenge to the financial sector of the introduction of faster, cheaper and human-centred financial services.

The term has become a buzzword among private and institutional investors who invested quite 50 The visionary statement made by Gates in 1994 that "banking is important, Strategic advisory firms have already put the emerging fintech trend at the top of their agendas, with the goal of providing universal banks with a better understanding of likely future scenarios. The growing interest in fintech will soon be visible in the academic literature, but there is currently a large knowledge deficit about this field.

\section{SIGNIFICANCE OF STUDY}

The goal of the research described during this paper was to fill a niche within the yet evolving and under-researched fintech literature by providing an alternate approach to understanding how the various ecosystems and layers of business 
- Key value drivers are identified by finding common trends in current research and also by building on the author's professional experience within the field.

- The paper supplies researchers, economists and financial professionals with a far better understanding of which areas of the world require further in-depth research, and offers a holistic understanding of the topic.

- It isn't the goal of this paper to supply an in-depth analysis of the precise domains fintech companies are operating in - like lending or payment transfers

- To generate an exclusive way of understanding the role that fintech can play within the financial sector, but rather to invoke new ideas by offering an alternate,

- Multi-layered evolutionary approach which will be used as a suggestion in further academic research into the topic.

\section{OBJECTIVES OF STUDY}

- Fintech - Use of digital technologies and innovation to support, enable or provide alternatives to traditional banking and financial services, like mobile wallet, contactless NFC technology, and crypto currency

- Traditional Collaboration - Three in four respondents of World Fintech Report survey identified collaborating with traditional financial service firms as primary business objective

- Mergers \& Acquisitions - More fintech companies like better to merge or get acquired by other fintech companies compared to being bought by traditional firm

- Key Growth Drivers - Include proliferation of fintech startups, growing adoption of digital banking technologies, and accelerating trend of innovative partnerships

\section{SCOPE OF THE STUDY}

- Albeit the research is predicated on a qualitative approach of conducting six interviews from industry experts within financial services industry in Ireland

- Fintech experts there are a couple of limitations from the research the time allowed for the research restricted the chance to interact and interview more Fintech start-up directors or owners.

- The research would have benefitted from an interview of a Fintech start-up whom became successfully globally

- There also are more Irish financial services companies which can have a rather different insight into the market and where Fintech is taking it within the future.

- The six candidates chosen during this short timeframe have provided a cultural insight across many various avenues within the industry. 


\section{LITERATURE REVIEW}

- The financial services industry is made up of economic services provided by the finance industry which include, credit unions, banks, financial institutions, accounting firms, real estate, consumer finance companies etc.

- The financial services trade is basically a financial service provide to customers or else businesses which in point of fact manage money.

- Even though we can sketch a version of the financial method back as far as the 1860 's, it was the nineties as soon as the industry really came to fruition

- The financial services business has witness significant change and alteration over the last little decades. Financial institution and banks have seen theatrical reform. There has been a mass convert of current banks and new entrant to the business

- The financial services became more prevalent in the United States and the world as a result of the Gramm - Leach - Bliley Act.

- It was through the Gramm - Leach - Bliley Act that started to change the landscape of financial services.

- Fintech has had a knock on effect throughout the world on financial services within the US and of course Europe. As discussed previously this has escalated dramatically since the financial crisis

\section{RESEARCH APPROACH}

The next element or layer of the onion is the type of approach the study will utilize. There are two types of research approaches namely inductive and deductive research.

\section{DEDUCTIVE APPROACH}

The most common view of the relationship between theory and research which the latter is conducted with reference to hypotheses and ideas inferred from the former. Deduction owes much to what we would think of as a scientific research. It simply involves the development of the theory that is then subjected to a rigorous test through a series of propositions.

\section{INDUCTIVE APPROACH}

An inductive argument is radically different from a deductive type as it does not have the same relationship between reasons and conclusions. Both an inductive and deductive research approach for this study. Researcher has adopted an inductive approach as this is more suited to qualitative research to use a variety of methods to collect data by studying a small sample of interviewees. This is mainly due to the majority of research following a qualitative method of interviews of senior leaders within the financial services industry.

\section{RESEARCH STRATEGY}

The next level in the research onion is looking at the research strategy. Describes the research strategy as a framework for the collection and analysis of data and that the choice of the research strategy reflects decisions about the priority being given to a range of dimensions of the research process.Fintech is having within technique in which an interviewee physically meets the respondent, reads them the same set of questions in a predetermined order, and records his or her response to each. 


\section{DATA COLLECTION METHODS \& DISCUSSIONS}

Data collection is an extremely important element of research as the research topic is investigative and exploratory in nature (investigating the impact financial technology is having in the financial services sector), the research method is qualitative. Also because the research techniques used are non-numerical or statistical in nature qualitative is more apposite to the subject than quantitative research.

\section{Primary Data}

The author also will undertake primary data collection as an important a part of the proposal. The researcher will plan to interview six experts within the financial services industry and Fintech. Therefore as in-depth interviews have been selected as the primary data collection method across financial services firms and industry experts in Ireland for this study, the technique collates qualitative data.

\section{Secondary Data Collection where Approach}

The researcher makes use of existing sources of data that are publicly available, also known as secondary sources of data. Secondary data relates to data originally collected for a few other purposes. This secondary data can include of company and industry specific organizational websites (internal secondary data), as well as any previous and relevant research papers or journal articles (external secondary data)

\section{Fintech Trends}

Will advancement within financial technology help your company plot a route risks while cutting costs? From the services you use to those you provide, these vanguard fintech trends may change the way you're doing business.

A catboats shift to middle-of-the-road and digital-only banks makes impression, authoritarian requirements, and customer expectations fuel innovation. The need for speed, security, and convenience are well-known but difficult to implement within the financial sector. However, this is often changing as more organizations invest in technologies that give them a foothold within the market. Plus, a rise in risk capital (VC) funding for fintech startups is spurring a replacement wave of services.

\section{Platform as a Service (paas) Offerings Expand}

Customers crave convenience. However, financial institutions struggle to satisfy their demand while safeguarding information. As banks suits evolving regulations, customers will enjoy the opening of APIs to customer data. Amid Pass, institutions can acclimatize to shifting needs with customized infrastructure that allows them to embrace cloud platforms fully. Statistical data shows, competitive public cloud PaaS revenue will reach 22.602 million in 2019 , up from 13.872 million two years ago. These services provide the infrastructure to perform a spread of tasks, including:

- Team collaboration

- $\quad$ Resource management

- $\quad$ Payment processing

- Credit risk management 


\section{Non-Traditional Banking Services Gain Credibility}

The fall of banks in 2008 led to a distrust that a lot of consumers haven't recovered from. This provides room for lots of business opportunities since digital-only banks use transparency as a point. However, slow adoption rates have plagued the industry.

A survey by Cornerstone Advisers finds, "fewer than 10\%" of these surveyed would consider a digital bank. Instead, virtual institutions look to spice up profits by offering supplementary services like financial tools developed for brand spanking new voice technologies

\section{Increase in Dependence on Intelligent Technologies}

Commencing customary establishment test robe advisors to higher algorithms assessing credit profiles, we'll see companies expand their use of intelligent technologies. The mixture of AI (AI), machine learning (ML), and robotic process automation (RPA) provides multiple benefits to those within the financial industry, such asA decrease in risk from loan defaults through the utilization of other credit decisioning models (ACD) that use ML. Smarter risk management that uses predictive and proactive models rather than reactive processes.rise in operational improvements resulting from data collection and analysis.Better customer experience through the adoption of virtual customer assistants (VCA).

\section{Mobile Payment Options Go Mainstream}

According to G2 Crowd, "the worldwide volume of mobile payments will grow by $60 \%$ over subsequent two years." Mobile banking puts control into the customer's hands while breaking down barriers to access. However, this Fintech trend covers a spread of payment options, including virtual currency and block chain. The Fintech Times calls these technologies an "Internet of Payments and each one among those choices change how consumers view mobile banking and fund transfers.

- Within the US, consumers feel comfortable with wallet-less options and rally behind big players, like Google and Apple.

- On a worldwide scale, access to payment options allows a greater number of people to interact with companies and complete everyday transactions without a typical bank account.

\section{New Benefits fromCrypto Currency and Block Chain Innovations}

The move towards block chain's use in financial institutions has been slow but remains a really important fintech trend. However, a Greenwich statement finds, "The financial services industry at the present spends $\$ 1.7$ billion once a year on block chain technology.

\section{Use of Regulatory Tech (RegTech) Grows}

Retch uses AI to automate risk assessments while delivering insights on big data. As data collection grows, the amount of regulations increases. With increased oversight, those within the financial industry feel the burden of compliance with various new regulations. 


\section{D. Umarani \& N.Subrahmanyam}

\section{Crypto Currency Inventions}

- While Face book's Libra holds public attention, many other organizations are busy deciding the way to leverage crypto currency to face up to future markets. In upcoming years, experts expect to see more interest in

- $\quad$ Stable coins. These are often flat-backed or backed by commodity and have a group price.

- Digital asset management. Look for banks to supply more options for managing crypto currencies.

- As financial institutions look to diversify across the world, we'll see virtual currencies, and therefore the availability of crypto lending continues to realize traction.

\section{CONCLUSIONS}

From the beginning of the introduction and literature review it's extremely clear that the financial services have seen dramatic change over the last sixty year; from the to the financial crisis and new innovative technology. Much of this alteration has come from the evolution of technology across every industry. Technology has grown at a rate that nobody could have predicted. Financial technology is not any different and it's changing the way financial services interact with consumers. The Literature Review was to realize insight knowledge to both the financial services industry and financial technology.

\section{REFERENCES}

1. Liu, J., Hebenton, B., \&Jou, S. (n.d.).Handbook of Asian Criminology.

2. Kharouni, L. (2012).Automating Online Banking Fraud Automatic Transfer System:The Latest Cybercrime Toolkit Feature (Rep.).

3. 3 Threats to the Financial Services sector (Rep.)(2014)PricewaterhouseCoopers.

4. News papers The Hindu

5. Elsevier International journal

6. Internationalfintechconfrence.com

7. The innovators, Rogues, and Strategists Rebooting Banking

8. Lamba, Pushp, And Shruti Pollock. "Digitization In The Retail Industry: Insights on the Possibilities Beyond E-Commerce \& the Driving Force Behind its Omni-Channel Growth." International Journal of Sales \& Marketing Management Research and Development (IJSMMRD) (2017).

9. Omolo, Anne Achieng. "Lending Model and Loan Repayment among Financial Institutions in Kakamega Municipality, Kenya." (2018). IMPACT : International Journal of Research in Business Management(IMPACT : IJRBM): 39-60 